\title{
GuIdO VIARO: MODERNIDADE NA ARTE E NA EDUCAÇÃO*
}

Dulce Regina Baggio Osinski**

\section{RESUMO}

Este trabalho analisa a contribuição de Guido Viaro para o ensino da arte do Paraná, como protagonista de diversas ações no campo educacional na cidade de Curitiba, marcadas pela identificação com a modernidade, pelo incentivo à liberdade e pela valorização da expressão individual, no período que vai desde a década de 30 até meados dos anos 1960 do século XX. Relacionando-se com intelectuais de outras áreas do conhecimento, Viaro participava do debate que então se colocava na educação, na literatura e na arte. Como educador, atuou em frentes diversas: com crianças, com professores e com estudantes de arte. A análise de sua trajetória intelectual procura relacionar suas idéias sobre arte e ações pedagógicas com o pensamento moderno da década de 40, apoiando-se no conceito de Gramsci do intelectual como um partícipe do processo de organização da cultura. Como fontes, foram utilizados artigos de jornais e revistas, projetos pedagógicos, documentos institucionais, programas de curso, atas e planos de aula, bem como fotografias, obras de arte e exercícios escolares.

Palavras-chave: Ensino da arte. Modernidade.

Este trabalho analisa a trajetória intelectual de Guido Viaro e sua contribuição para o ensino da arte no Paraná. Considerado por muitos o responsável pela introdução do Paraná na modernidade das artes plásticas, Viaro, que nasceu em 1897 em Badia Polesine, pequena localidade da província do Vêneto, na Itália, chegou ao Brasil em 1927, estabelecendose em Curitiba em 1930, onde faleceu em 1971. Artista conhecido por

\footnotetext{
* Artigo recebido em 2/5/2007 e aprovado em 22/8/2007.

** Doutora em Educação pelo Programa de Pós-graduação em Educação da UFPR. E-mail: dulceosinski@ufpr.br
} 
meio de obra gráfica e pictórica, descobriu no campo educacional novas possibilidades de intervenção social, cujas ações, circunscritas à cidade de Curitiba, compreendem o período que vai desde a década de 30 até meados dos anos 1960 do século XX. Colaborador da revista Joaquim, que circulou em Curitiba entre os anos 1946 e 1948, Viaro se relacionava com intelectuais de outras áreas do conhecimento, como Dalton Trevisan e Erasmo Pilotto, participando do debate que então se colocava na educação, na literatura e na arte. Em alguns períodos, Viaro utilizou meios como jornal ou revistas especializadas para dar publicidade às suas idéias e reafirmar posicionamentos políticos através de textos críticos e de crônicas enfocando peculiaridades do meio artístico.

Como educador no campo da arte, atuou em frentes diversas: com o trabalho dirigido às crianças, que se iniciou em 1937 no Colégio Belmiro César, culminando com a criação, em 1953, do Centro Juvenil de Artes Plásticas; com a formação de professores, tendo, em parceria com o Instituto de Educação do Paraná, coordenado os primeiros cursos de capacitação docente em arte do Estado; com o ensino livre de arte, ministrado em seu ateliê; e com o ensino superior, na Escola de Música e Belas Artes do Paraná, fundada em 1948.

Na presente análise, defende-se a tese de que Guido Viaro foi partícipe de um movimento que visava instituir um projeto artístico e educativo original para o contexto paranaense, projeto este identificado com o moderno e em permanente diálogo com o pensamento de intelectuais envolvidos com arte e educação em nível nacional e internacional, apoiado nos seguintes pressupostos: valorização da individualidade, da liberdade de expressão na arte, da experimentação e do universalismo. Além disso, busca também relacionar o pensamento moderno veiculado na Curitiba da década de 40 e defendido pelos intelectuais da época com as idéias e ações pedagógicas desse educador em arte, identificando as relações possíveis entre obra, ações educacionais e escritos sobre os temas de arte e educação, e objetivando o estabelecimento de uma trama contextual na qual as ações de Viaro estavam inevitavelmente enredadas.

O período em questão para o estudo que se pretende, em especial a década de 40, foi no Paraná, e especificamente em Curitiba, caracterizado por uma efervescência de manifestações vinculadas à idéia de moderno, que tiveram seu ponto áureo na literatura, mas que também se 
mostraram presentes nas artes plásticas, tendo como veículo privilegiado a revista Joaquim, caracterizada por um tom muitas vezes agressivo. Da mesma forma, a obra artística de Guido Viaro motivou toda uma geração de artistas preocupados em sintonizar a produção artística do Paraná com as tendências a ela contemporâneas. Mas foi também por meio da educação, tanto quanto por meio da expressão artística, que seu pensamento moderno pôde se afirmar com bastante vigor.

No entanto, sua posição como intelectual e as ações decorrentes das opções que tomou no campo das idéias não representam um fenômeno isolado, sendo antes resultados de um meio social intelectual fecundo e aberto a mudanças e transformações, ainda que setorizado e restrito em comparação à população como um todo. Seu relacionamento com Erasmo Pilotto, intelectual paranaense da educação que sempre esteve próximo da produção artística local, colocou-o em contato com o ideário das renovações que a Escola Nova professava. O debate promovido, no período, entre artistas, escritores e educadores de diversas áreas, e no qual a tônica dominante era a construção de uma realidade de novo tipo, acabou resultando em projetos culturais e educacionais, viabilizados graças a esforços conjuntos e ao empenho de uma elite intelectual com poder de direção e posicionada de forma a possibilitar que idéias se concretizassem.

Optando por transitar no campo da história dos intelectuais, com ênfase para suas idéias e ações educativas, adotou-se o conceito de intelectual de Gramsci, que o pensa necessariamente engajado no meio social e interventor no processo de organização da cultura. Para Gramsci, a idéia de intelectual está mais fundamentada na função desempenhada na sociedade do que em características específicas predeterminadas: "Todos os homens são intelectuais, mas nem todos os homens têm na sociedade a função de intelectuais" (GrAMSCI, 2004, p. 18). Contrapondose ao que denominava intelectual tradicional, ocupado apenas com sua obra e suas idéias e desinteressado da vida prática, esse pensador defende que o novo intelectual deveria "imiscuir-se ativamente na vida prática, como construtor, organizador, "persuasor permanente"” (GRAMSCI, 2004, p. 53). Como o objeto de análise é a trajetória de um artista-educador, entende-se que trabalho intelectual e manual não podem ser dicotomizados. Pensamento, ações pedagógicas e produção artística apresentam, nesse caso, proximidades que não podem ser ignoradas. 
A vontade de estar em sintonia com a modernidade foi por um longo período histórico um fator mobilizador para grupos e tendências intelectuais de tradições diversas. Motivados pela crença no progresso e na necessidade de intervenção sobre o mundo e sobre a sociedade, esses intelectuais se consideravam especialmente competentes para lidar com a cultura e empreender as mudanças sociais necessárias, imbuídos de sentimento de missão social que tinha como principal pressuposto a defesa da centralidade da questão educativa/formativa (VIEIRA, 2006, p. 3).

É essa idéia do intelectual comprometido com seu meio social e envolvido num trabalho cotidiano de reformulações culturais identificado com a modernidade que nos interessa na análise da trajetória de Guido Viaro, em especial com relação às idéias convertidas em ações políticas em prol da educação em arte. Não obstante, a adoção dessa perspectiva requer um investimento a respeito dos conceitos de modernização, modernidade e modernismo, termos que coexistem e se inter-relacionam, assumindo significados ora bastante próximos, ora consideravelmente distintos, dependendo dos autores consultados.

O processo de modernização é um fenômeno palpável e passível de ser determinado cronológica e geograficamente, definido por autores como Norberto Bobbio (1997) e Marshall Berman (1986) como o conjunto de processos e mudanças operadas nas esferas política, econômica e social que têm caracterizado os dois últimos séculos, sendo um fenômeno complexo, de amplo fôlego e multidimensional que acontece em períodos de tempo diferentes e abrange todos os setores do sistema social. A principal conseqüência da modernização econômica acelerada foi justamente a transformação dos princípios do pensamento racional em objetivos sociais e políticas gerais contaminados pela idéia de progresso. Já a modernidade, de contornos imprecisos e definições múltiplas, tem características que variam de lugar para lugar, e apresentam temporalidades distintas de acordo com a localização. Para Berman (1986), modernidade seria um conjunto de experiências de tempo e espaço, de si mesmo e dos outros, das possibilidades e dos perigos da vida, sem fronteiras geográficas, raciais, de classe, de nacionalidade, de religião ou de ideologia, compartilhadas por homens e mulheres em todo o mundo. O desejo de transformação de si próprio e do mundo em redor, juntamente com o terror da desorientação e da desintegração da vida, seriam algumas das preocupações especificamente modernas, as quais prevêem necessariamente a convivência com o paradoxo e com a 
contradição. No entanto, como bem assinala Touraine (1994), a modernidade não pode ser concebida separada da modernização, mas sua concepção se reveste de especial importância no século XX, um período em que o progresso não se encontra presente apenas nas idéias, mas também nas formas de produção e trabalho. No entanto, concebê-la simplesmente como a eficácia da racionalidade instrumental significaria apreendê-la apenas parcialmente, obscurecendo a outra metade: o surgimento do sujeito como liberdade e como criação.

Com relação ao termo modernismo, ele tem sido freqüentemente usado para sugerir o perfil geral das artes do século XX, sendo também empregado para isolar e destacar uma corrente específica num determinado período. Abrangendo uma ampla variedade de movimentos de subversão das tendências realistas e românticas, a palavra modernismo abriga num mesmo arcabouço pensamentos não-pertencentes ao mesmo gênero e muitas vezes contrapostos entre si, mas que trazem em comum a busca incessante pelo novo, numa interminável e permanente revolução contra a totalidade da vida moderna (BERMAN, 1986, p. 29).

Desejo do novo, orientação para o futuro e crítica aos conceitos e às práticas estabelecidos são ingredientes constantes do discurso moderno, que contempla também, com freqüência, o desencanto com a vida industrializada, a crítica ao progresso descontrolado e a defesa da justiça social. Para Guido Viaro e o meio intelectual com o qual ele dialogava, esses elementos não só são parte integrante de suas práticas e idéias. Mais que isso, o diálogo com a modernidade constitui estratégia de autorepresentação como alternativa possível dentro de um universo dominado pela tradição. A afirmação desses artistas e intelectuais como modernos e como atores no processo de transformação social não se limita às obras realizadas em seus campos de ação cultural. Em muitos casos, sentem como necessária uma intervenção mais palpável e de maior abrangência, vendo na educação um dos meios de concretização da modernização almejada. Imerso nesse turbilhão de dizeres e modos de expressar a idéia de moderno, Guido Viaro não só fazia de sua obra um ícone de modernidade de que se serviam os jovens artistas, mas se envolvia constantemente em projetos apoiados em idéias modernas, defendendo também a liberdade de expressão dentro do sistema escolar.

Entretanto, pensar Guido Viaro como um moderno em relação ao seu contexto exige que se tomem algumas precauções. É fundamental que a análise da modernidade cultural brasileira, seja nas artes, seja na 
educação, leve em conta o processo de modernização experimenciado no Brasil, não se limitando às categorias determinadas pelos modelos europeus. Não menos relevante, além dos resultados propriamente ditos, também é o desejo de modernidade expressado pelos protagonistas e a percepção de sua produção, por parte do público e da crítica, como um elemento de distúrbio (FABRIS, 1994, p. 23). Essa modernidade, não raro, se dá em constante tensão com a tradição, como é o caso de Guido Viaro, ou é estimulada por disputas pelo poder dentro do âmbito da cultura. Assim, o moderno se constrói ora de forma confrontadora, ora por entre tênues linhas que separam pólos de oposição como velhos versus moços, acadêmicos versus modernos, escola versus autodidatismo, nunca absoluto, sempre contraditório e rico em gradações.

Como fontes para a realização deste trabalho, foram utilizados documentos de naturezas diversas, que incluem: catálogos de exposições de arte realizadas no período estudado; cartas, bilhetes e documentos oficiais datilografados e manuscritos do Centro Juvenil de Artes Plásticas, da Secretaria de Educação e Cultura do Paraná, do Instituto de Educação do Paraná e do Colégio Estadual do Paraná; decretos-leis e portarias do estado do Paraná; entrevistas e depoimentos de ex-alunos, colegas, amigos e familiares de Guido Viaro; imagens de obras de arte publicadas na revista Joaquim e de pinturas realizadas pelas crianças freqüentadoras do Centro Juvenil de Artes Plásticas; fotografias de atividades pedagógicas no Centro Juvenil de Artes Plásticas e na Escola de Música e Belas Artes do Paraná; artigos publicados nos jornais paranaenses Gazeta do Povo, Diário da Tarde, Diário do Paraná, O Dia, Jornal do Estado e $O$ Estado do Paraná, pesquisados nos arquivos da Biblioteca Pública do Paraná, do Museu de Arte Contemporânea do Paraná, do Centro Juvenil de Artes Plásticas e do Centro de Documentação e Pesquisa Guido Viaro; e artigos publicados nos periódicos Joaquim, Illustração Paranaense, A Ilustração e Ilustração Brasileira. Essas fontes, em sua diversidade, expressam as idéias e a trajetória de Viaro como partícipe de projetos formativos, revelando também a presença impessoal e dispersa dos discursos artístico e educativo.

A idéia de Guido Viaro como artista moderno e educador identificado com as tendências renovadoras, embora assumida pelo artista desde sua chegada a Curitiba, não se consolida num curto prazo - mas é fruto de uma longa trajetória que soma seu trabalho como artista, suas 
intervenções educativas e a percepção paulatina do meio cultural a respeito dessa representação.

O desejo de integração ao ambiente que escolheu para se fixar levou-o, desde os primeiros tempos, à busca de relacionamentos com intelectuais e artistas, procurando sempre inteirar-se dos problemas do país que o acolheu. Participar de exposições individuais e coletivas, de associações de artistas e de eventos, como os salões de arte, primeiro como artista, depois como membro de júri, foram formas de se fazer presente na cena cultural local e de se imiscuir em sua realidade.

Tentando fazer parte de um meio dominado, no campo das artes plásticas, pela supremacia do artista norueguês Alfredo Andersen e seus discípulos, radicado em Curitiba, Viaro procurou destacar-se pelo contraste com aquele tipo de arte que tinha na tradição um dos motivos de orgulho. As freqüentes referências sobre sua pessoa, como rebelde e insatisfeito, e sobre sua obra como moderna, marcada pela experimentação e pela subjetividade, são alguns indícios dessa estratégia de afirmação. Oferecendo-se como a possibilidade do novo, procurava tecer vínculos com aqueles artistas que já gozavam de prestígio e respeito, o que lhe rendeu o reconhecimento como artista paranaense digno de representar o estado em exposições e outros eventos, ocorrendo deslocamento progressivo da posição de estrangeiro e artista marginal para a de protagonista da cena artística.

Iniciando sua carreira docente em colégios, ministrando a disciplina de desenho, conformada curricularmente dentro de conteúdos rígidos como o desenho geométrico, a rede estimográfica e as faixas decorativas, Viaro não tarda a descobrir na ação educativa um importante meio de intervenção social. A iniciativa de criação da Escola de Desenho e Pintura, espaço de aprendizagem que misturava idades e classes sociais e que acabou se tornando ponto de encontro de intelectuais e artistas como Erasmo Pilotto, João Turin, Dalton Trevisan e Miguel Bakun, possibilitou que suas idéias sobre o ensino da arte, baseadas no encorajamento da individualidade e na valorização da expressão pessoal, fossem postas em prática. Trabalhando a partir da observação do natural, futuros artistas como Leonor Botteri, Nilo Previdi e Esmeraldo Blasi iniciavam na arte ouvindo o conselho máximo: Nunca copiar, mas interpretar. Sem receberem muitas correções, esses aprendizes eram responsáveis pelas próprias descobertas, avançando de acordo com seu interesse. 
No Colégio Belmiro César e no Colégio Estadual do Paraná, locais em que lecionava a disciplina de desenho, a alternativa encontrada foi a organização de atividades extracurriculares, freqüentadas pelos estudantes no contraturno. Com freqüência livre e pouca interferência do professor, essas atividades tinham como norte a liberdade de expressão. Esse contato com os jovens, iniciado por meio da profissão docente, intensificou-se em meados dos anos quarenta, contribuindo para sua inserção nos debates que opunham o velho e o novo, a tradição e a modernidade, o passado e o futuro. Viaro se dedica aos moços, opta por eles, apóia suas iniciativas ousadas e recebe em troca o reconhecimento de sua obra e a escolha de sua figura como ícone moderno das artes plásticas. Seu temperamento atraiu aqueles artistas e intelectuais iniciantes à procura de um escudo para a defesa de suas causas renovadoras. Mais velho e experiente, o artista não deixava, porém, de dispensar aos seus novos amigos um tratamento igualitário, refutando o tom autoritário do mestre e se colocando como alguém que ainda procura, que está sempre em processo. Seu humor irreverente, que não poupava nem ele próprio, também o aproximava daqueles que buscavam a ruptura com o estabelecido. Os moços se identificam com sua obra, cujos temas, por vezes rudes e realistas, traziam a marca das preocupações sociais, e cujo tratamento, com pinceladas mais livres do que se praticava entre os artistas conhecidos na cidade, trazia promessas de caminhos pessoais a serem seguidos.

Para Dalton Trevisan, criador da revista Joaquim, Viaro era perfeitamente talhado para representar o papel de símbolo da modernidade paranaense das artes plásticas. Sua estratégia foi opor a figura daquele considerado portador da arte nova dos tempos novos com a de Andersen, rebaixado por ele a representante de uma arte superada. Carregando nas tintas na avaliação dos dois artistas, Trevisan forçava uma polarização que servia muito bem aos seus propósitos de instituição de um novo grupo na cena artística. A construção dessa imagem é fortemente reforçada por críticos como Wilson Martins, Sérgio Milliet e Nelson Luz, contando também, em algumas ocasiões, com a conivência de Viaro.

Qualificado como portador das idéias modernas em Curitiba, Viaro, de qualquer forma, aproveita o espaço aberto pela Joaquim para suas experiências inovadoras, seja na produção de imagens, sua maior contribuição, na publicação de textos ou na concessão de entrevistas. 
Suas gravuras abusam do contraste de claro-escuro e dos temas sociais, como o fazem os demais artistas que participam do projeto, como Poty Lazzarotto, Lasar Segall, Renina Katz e Esmeraldo Blasi, Portinari, entre outros, e contribuem para uma maior aproximação com a estética moderna. A opção desse grupo de artistas era uma modernidade de caráter figurativo e tendência expressionista, campo em que Viaro se sentia à vontade e com cuja visualidade se encontrava plenamente sintonizado.

Por meio da Joaquim, Viaro também participou dos debates que ali se empreendiam, envolvendo arte e literatura, e que tinham como participantes Carlos Drummond de Andrade, Oswald de Andrade, Vinicius de Moraes, Mário Pedrosa, Antonio Candido, além das contribuições feitas por traduções de autores como John Dewey, André Gide, Jean-Paul Sartre, Merleau-Ponty, T.S. Elliot e Virgínia Woolf. As discussões, que abrangiam assuntos como o romance, a poesia, as artes plásticas e a música, versavam freqüentemente sobre temas mais pontuais, como o papel dos intelectuais na cena pública. Avesso a qualquer regionalismo, especialmente ao paranaense, representado pelos paranistas e pelos partidários de Andersen, o periódico colocava o Paraná como uma província atrasada, lugar da estagnação e da infertilidade, contrapondo-se às grandes metrópoles, reverenciadas como prenhes de vida cultural efervescente. Reconhecendo as carências do meio e acreditando que as importações de artistas, críticos e idéias deveriam acontecer para remediar essa situação, Viaro não se limitou às críticas, mas partiu para a ação, assumindo novas tarefas como a de escrever textos sobre a produção artística paranaense, nos quais a formação autodidata, a subjetividade e os elementos psicológicos eram sempre valorizados. Convicto de que seu caminho era o da figuração expressionista, não deixou de apoiar o abstracionismo emergente na Curitiba dos anos sessenta. Avesso à arte engajada, a serviço de partidos ou ideologias, não se furtou, porém, a cumprir seu papel de organizador de uma cultura que se pensava tão precária.

As idéias discutidas tantas vezes na Joaquim a respeito de uma missão dos intelectuais, especialmente dos intelectuais modernos, expressas em seu desejo de promover mudanças sociais visando um mundo melhor e tendo na cultura um de seus pilares estruturais, penetraram em Viaro de forma intensa, sendo alimentadas, no campo educacional, por educadores como Erasmo Pilotto, Eny Caldeira e Adriano Robine. Por meio desses interlocutores, ampliou-se seu universo 
teórico, passando a ter contato com o pensamento de intelectuais como John Dewey, Piaget, Montessori e, mais tarde, por meio de leituras, também de Herbert Read, Lowenfeld e Anísio Teixeira, todos eles interessados não só na defesa da centralização do processo educativo no indivíduo, mas também na afirmação da importância da experiência artística para a sua formação.

A criação do Centro Juvenil de Artes Plásticas (CJAP) foi assim o ponto culminante de uma série de projetos nos quais Viaro esteve direta ou indiretamente envolvido, como suas atividades extracurriculares em escolas regulares, as exposições de arte infantil realizadas em Curitiba desde os primeiros anos da década de 1940, as reformas para a educação propostas por Erasmo Pilotto e Emma Koch ou a coluna de jornal Gurizada, vamos Desenhar!, de autoria de Pilotto em colaboração com o artista. No espaço do CJAP, foi possível colocar idéias em prática e confrontar-se com a realidade social que as recebia. O Centro Juvenil tinha alguns pontos em comum com a Escolinha de Artes do Brasil, fundada no Rio de Janeiro por Augusto Rodrigues, e com outras escolinhas similares em outras cidades do país, como a defesa da espontaneidade e da livre expressão, e a preservação da pureza infantil em suas manifestações artísticas. No entanto, a instituição idealizada por Viaro diferia destas por não preservar a independência e o distanciamento da escola. A preocupação com a inserção de alunos dos grupos escolares em seu projeto esteve presente desde o início, sendo eles privilegiados nas visitas para os testes, ocasiões em que os futuros participantes eram selecionados para as atividades gratuitas. Os cursos de preparação para professores, que começaram a ocorrer quase simultaneamente ao trabalho com as crianças, também tinham como foco as professoras normalistas de escolas públicas, instituições tidas como lugares ideais para o exercício da liberdade de idéias, da criação artística e para a realização de experiências inovadoras.

Se à criança deveria ser garantida total liberdade, a escolha das profissionais orientadoras e a sua preparação para a função deveriam ser feitas com base no princípio de não-interferência. Conhecedoras da alma infantil, teriam bagagem pedagógica para incentivar os arroubos expressivos da criança e desencorajá-la a seguir caminhos pouco criativos. Não obstante, os cursos pensados para professores, embora investissem nesse caminho, procuravam contemplar igualmente os currículos ainda vigentes nas escolas, em que conteúdos rígidos ligados 
ao desenho ainda prevaleciam. Dessa mistura entre dois ingredientes de natureza diversa nascia o professor especializado em desenho, que deveria, de acordo com as expectativas de Viaro, atuar como disseminador de suas idéias para o ensino da arte para além do CJAP.

A ação de Viaro no Centro Juvenil de Artes Plásticas é um testemunho de suas crenças de que o papel do artista/intelectual diante do meio cultural que o abriga vai além da idealização de projetos baseados em idéias etéreas. Administrando a instituição, o artista enfrentou muitas vezes problemas ligados ao controle de freqüência e horários das professoras, à organização das atividades cotidianas ou das exposições escolares da instituição.

Consideradas vitrines das idéias modernas da arte e da educação, e incentivadas por órgãos internacionais como a Unesco, que acreditava serem elas capazes de contribuir para a melhoria do mundo, as exposições de arte infantil foram uma das principais atividades extracurriculares que faziam parte dos cronogramas do CJAP. O contato direto e a exposição visual dos argumentos se mostravam poderosas armas de convencimento de um público muitas vezes vacilante. As relações que se fazia com a arte primitiva, descoberta pelas vanguardas, e por algumas correntes artísticas como o expressionismo, defendidas por críticos de arte do período, aproximavam as manifestações de arte infantil de intelectuais e artistas no mundo todo. Fazendo parte desse processo, crianças paranaenses participavam de exposições em outras cidades do Brasil e do mundo, e em troca recebiam desenhos de crianças desses lugares, comungando, diante dos olhos extasiados dos educadores aqui e lá, da mesma expressão livre e da mesma ludicidade no tratamento do trabalho, características que os uniam pela universalidade. Não obstante, a análise desse discurso permite perceber que havia também condicionantes para uma expressão livre, impostos por aqueles que realizavam as seleções para as exposições, determinavam quais os trabalhos dignos de figurar em tais eventos e quais que deveriam ser excluídos. No caso das exposições internacionais, interessadas defesas da paz, temas de guerra eram proibidos, o que é expresso nos regulamentos e se pode perceber nos artigos de jornais da época. No caso de Viaro, os limites se estendiam às cópias, aos desenhos feitos a partir de referenciais externos, como revistas, e à linguagem das histórias em quadrinhos. Mesmo que de maneira sutil e pouco impositiva, os alunos eram também direcionados tematicamente. Os testes realizados para 
selecionar alunos para a escola também se mostravam contraditórios nesse sentido, servindo de instrumento para a escolha de crianças mais capazes de se expressar livremente que outras. Finalmente, o costume do artista de trabalhar em sua obra no espaço das aulas criava como quê um modelo involuntário do tipo de pincelada, traçado ou temática preferíveis - vinculado, obviamente, à sua própria obra.

Em toda a sua trajetória desde a chegada a Curitiba, pode-se perceber uma proximidade de Viaro com a esfera estatal. O artista assume cargos públicos, dos quais sobrevive, e de onde viabiliza os seus projetos. O Estado patrocina e apóia, emprega e movimenta culturalmente a cidade. O desejo de que o Estado torne concretos sonhos da elite cultural paranaense, como o da criação de uma escola de artes, não era uma posição isolada do artista, pois remontava aos tempos de Andersen, perpetuando-se entre seus seguidores e mesmo entre os intelectuais independentes. É uma escola de belas artes oficial e mantida pelo Estado que eles reivindicam, é também um Salão Paranaense de Artes oficial que buscam instituir. Esse diálogo com a esfera pública, por vezes difícil, outras vezes mais fluido, tornou possível que nos anos quarenta e cinqüenta alguns desses desejos fossem concretizados.

Um professor que acreditava que arte não se ensina e que passou grande parte de sua vida ensinando; um apologista do autodidatismo que nunca deixou seu posto de professor dentro de uma escola formal de arte; um moderno que dialogava com a tradição - partícipe de um projeto renovador para a arte e para a educação -, Guido Viaro o revela em suas múltiplas facetas: como artista, como educador e como organizador da cultura.

\section{ABSTRACT}

This study analyzes Guido Viaro's contribution to the teaching of art in Paraná, as the protagonist of different activities in the educational sphere in Curitiba, which were characterized by their identification with modernity, their incentive to freedom and appreciation of individual expression from the 1930s until the mid 1960s. Mixing with intellectuals from other fields of knowledge, Viaro participated in the debate taking place in education, literature and art, at that time. As an educator, he was active on different fronts: with children, teachers and art students. An analysis of his intellectual journey seeks to relate his ideas on art and pedagogical action to the modern thought of the 40s, based on Gramsci's concept of the intellectual as participant in the process of cultural 
organization. Newspaper and journal articles, pedagogical projects, institutional documents, course programs, minutes and class plans as well as photographs, works of art and school exercises were all used as sources.

Key words: the teaching of art; modernity, Gramsci.

\section{REFERÊNCIAS}

BERMAN, M. Tudo que é sólido desmancha no ar: a aventura da modernidade. Tradução de Ana Maria L. Loriatti e Carlos Felipe Moisés. São Paulo: Companhia das Letras, 1986.

BOBBIO, N. Os intelectuais e o poder. Dúvidas e opções dos homens de cultura na sociedade contemporânea. Tradução de Marco Aurélio Nogueira. São Paulo: UNESP, 1997.

FABRIS, A. Modernidade e vanguarda: o caso brasileiro. In: FABRIS, A. (Org.). Modernidade e modernismo no Brasil. Campinas: Mercado de Letras, 1994. p. 9-26.

GRAMSCI, A. Cadernos do Cárcere. Tradução de Carlos Nelson Coutinho. Rio de Janeiro: Civilização Brasileira, 2004. v. 2.

TOURAINE, A. Crítica da modernidade. Tradução de E. F. Edel. Petrópolis, RJ: Vozes, 1994.

VIEIRA, C. E. Intelectuais e o discurso da modernidade na I Conferência Nacional de Educação (Curitiba, 1927). Ampliado a partir do texto O discurso de modernidade na I Conferência Nacional de Educação (Curitiba - 1927) apresentado no III Congresso Brasileiro de História da Educação, realizado em Curitiba, em 2004. Curitiba, 2006. 